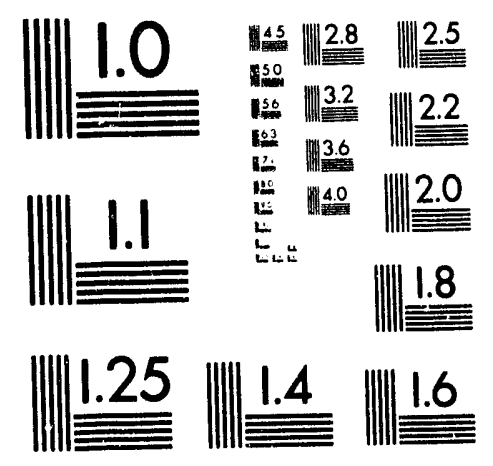



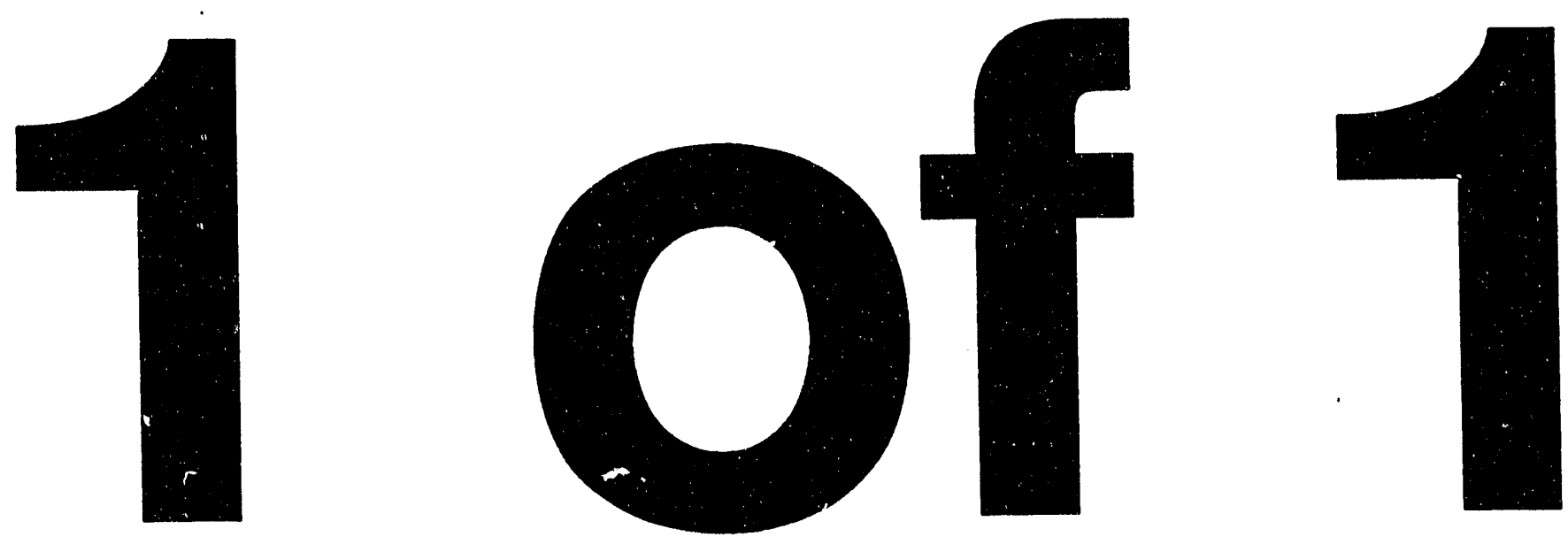


\section{CONTINUOUS EXTRACTION OF \\ Argonne National Laboratory \\ Chemical Technology Division \\ 9700 South Cass Avenue \\ Argonne, Illinois 60439} MOLTEN CHLORIDE SALTS WITH LIQUID CADMIUM ALLOYS* AUG 301993

L. S. Chow, J. K. Basco, J. P. Ackerman, and T. R. Johnson

OSTI

To be presented at

GLOBAL '93

International Conference and Technology Exhibition

Seattle, Washington

September $12-17,1993$

\section{DISCLAIMER}

This report was prepared as an account of work sponsored by an agency of the United States Government. Neither the United States Government nor any agency thereof, nor any of their employees, makes any warranty, express or implied, or assumes any legal liability or responsibility for the accuracy, completeness, or usefulness of any information, apparatus, product, or process disclosed, or represents that its use would not infringe privately owned rights. Reference herein to any specific commercial product, process, or service by trade name, trademark, manufacturer, or otherwise does not necessarily constitute or imply its endorsement, recommendation, or favoring by the United States Government or any agency thereof. The views and opinions of authors expressed herein do not necessarily state or reflect those of the United States Government or any agency thereof.

*Work supported by the U.S. Department of Energy, Nuclear Energy Research and Development Program, under Contract W-31-109-Eng-38. 


\title{
CONTINUOUS EXTRACTION OF MOLTEN CHLORIDE SALTS WITH LIQUID CADMIUM ALLOYS
}

\author{
L. S. Chow, J. K. Basco, J. P. Ackerman, and T. R. Johnson \\ Argonne National Laboratory \\ Chemical Technology Division \\ 9700 South Cass Avenue \\ Argonne, Illinois 60439
}

\section{ABSTRACT}

A pyrochemical method is being developed at Argonne National Laboratory (ANL) to provide continuous multistage extractions between molten chloride salts and liquid cadmium alloys at $500^{\circ} \mathrm{C}$. The extraction method will be used to recover transuranic (TRU) elements from the process salt in the electrorefiner used in the pyrochemical reprocessing of spent fuel from the Integral Fast Reactor (IFR). The IFR is one of the Department of Energy's advanced power reactor concepts. The recovered TRU elements are returned to the electrorefiner. The extracted salt undergoes further prncessing to remove rare earths and other fission products so that most of the purified salt can also be returned to the electrorefiner, thereby extending the useful life of the process salt many times.

\section{INTRODUCTION}

This article describes a pyrochemical method of continuous, multistage extractions between molten chloride salts and liquid cadmium alloys at $500^{\circ} \mathrm{C}$. This method, currently being investigated at Argonne National Laboratory (ANL), provides a means to recover transuranic (TRU) elements from the process salt discharged from the electrorefiner of an Integral Fast Reactor (IFR). Electrorefining is a key step in the pyrochemical reprocessing of spent IFR fuel. Rare earth fission products are removed from the salt as nearly a TRU-free waste form. The TRU elements are returned to the electrorefiner, thereby extending the useful life of the process salt many times.

The IFR is an advanced reactor concept ${ }^{1,2}$ in which TRU elements can be burned, or if desired, it can convert natural or depleted uranium to plutonium, thereby producing more fuel than it consumes and extending the life of the U.S. uranium reserves by about a hundredfold. ' The IFR incorporates (a) metallic driver and blanket fuels, (b) an inherently safe, liquidsodium-cooled, pool-type, reactor design, and (c) onsite pyrochemical processing of spent fuels and wastes. The use of metal fuel offers safety benefits because the thermal conductivity of metal fuel is about ten times that of oxide (ceramic) fuel. In addition, the recycling of spent metal fuel is cost effective because it is a relatively simple process. The large pool of liquid sodium acts as a large heat sink, which can remove the excess heat from the fuel efficiently without a significant rise in temperature. This feature helps ensure safe operation for the reactor under off-normal conditions. Electrorefining ${ }^{3}$ is a key step used in the pyroprocess of the IFR to separate the actinides from the fission products in the spent fuel. The electrorefiner (Fig. 1) is a steel vessel that contains a pool of liquid cadmium and an electrolyte of moiten $\mathrm{LiCl}-\mathrm{KCl}$ eutectic. The electrolyte contains $2 \mathrm{~mol} \%$ actinides at $500^{\circ} \mathrm{C}$. Spent fuel and its iron-chromium alloy cladding are chopped and placed in steel anode baskets, which are then immersed in the electrolyte of the electrorefiner. Actinides in the spent fuel are recovered by electrotransport through the molten chloride electrolyte salt to cathodes. The fission products, with the

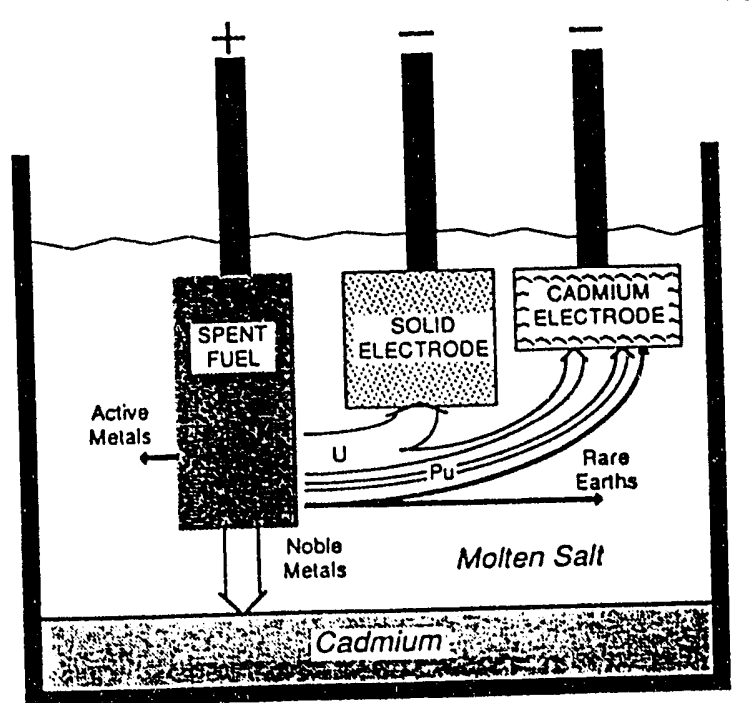

Fig. 1. Schematic of Electrorefiner 
exutption of tritium, krypton, and xenon, accumulate in the electrorefiner during the process. The alkali metals, alkaline earths, and rare earth fission products remain in the salt. Noble metal fission products and zirconium from the fuel alloy remain in the cadmium pool. Periodically, the salt and cadmium are removed from the electrorefiner, treated to separate fission products, and returned to the electrorefiner.

Calculations ${ }^{4}$ were made to determine the amounts of spent salt and metal to be discharged from the electrorefiner after several electrorefining cycles. Estimated results (shown in Table 1) are based upon processing $500 \mathrm{~kg}$ of actinides from core and blanket fuels with an overall average burnup of $60,000 \mathrm{MWD} / \mathrm{T}$ of actinides. Figure 2 illustrates typical process steps to treat the spent salt and metal to recover TRU elements, salt, and cadmium for return to the electrorefiner, and to prepare high-level waste forms for the remaining salt and metal. 5 Spent salt from the electrorefiner first goes through a partial reduction process with $\mathrm{Cd}-\mathrm{Li}$ alloy, an extraction step with $U$ in $\mathrm{Cd}$, and a stripping step with $\mathrm{Li}$ in $\mathrm{Cd}$. Each reduction, extraction, and stripping step uses several countercurrent high-temperature centrifugal contactors as the contacting equipment. The reduction, extraction, and stripping steps essentially remove all of the actinides from the salt to the cadmium and leave about $83 \%$ of the rare earths in the salt. Actinides in the product cadmium solution are oxidized back into salt with $\mathrm{CdCl}_{2}$ and returned to the electrorefiner; the metal stream is processed to recycle the cadmium and to incorporate the rare earths and traces of TRU in the metal waste form. The salt is passed through zeolite beds to remove the remaining fission products. This paper describes the contacting equipment used in the salt treatment process. Further discussions of the flowsheet and the waste forms are given in companion papers. ${ }^{6.7}$

Table 1. Spent Fuel and Cadmium Discharges from Electrorefiner After Processing $500 \mathrm{~kg}$ Actinides

\begin{tabular}{|c|c|c|c|}
\hline Salt & $\begin{array}{c}\text { Weight of } \\
\text { Chloride } \\
(\mathrm{kg})\end{array}$ & Metal & $\begin{array}{c}\text { Weight of Metal } \\
(\mathrm{kg})\end{array}$ \\
\hline LiCl. $\mathrm{KCl} \cdot \mathrm{NaCl}$ & 445 & $\mathrm{Cd}$ & 87 \\
\hline RbCl.CsCl & 20 & $\mathrm{Zr}$ & 2 \\
\hline Stabie Chlorides ${ }^{3}$ & 16 & Noble Metals & 11 \\
\hline (Rare Earth)Cl $_{3}$ & 15 & & \\
\hline UCl $_{3}$ & 1 & $U$ & 0 \\
\hline (TRU)Cl & 3 & TRU & 0 \\
\hline Tolals & 500 & & 100 \\
\hline
\end{tabular}

"Includes $\mathrm{SrCl}, 8 \mathrm{aCl}_{2}, \mathrm{YCl}_{3}, \mathrm{SmCl}_{2}$, and $\mathrm{EuCl}_{2}$.

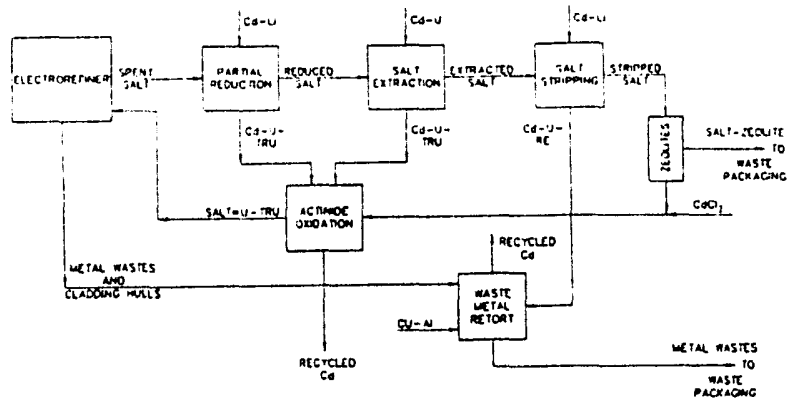

Fig. 2. Proposed Flowsheet for Treating IFR Spent Salt and Metal

\section{CHEMICAL BASIS OF SALT EXTRACTION PROCESS}

The salt extraction process and the electrorefining process are based upon differences in the distribution of metallic elements dissolved in cadmium and their chlorides dissolved in a mixture of stable alkali metal and alkaline earth chlorides. ${ }^{8}$ Equilibrium among the elements that distribute between the phases is achieved by exchange reactions between cations in the salt and metal atoms in the cadmium. At equilibrium, the actinides prefer the liquid cadmium metal phase, while the rare earths prefer the salt. Uranium, TRU elements, and most rare earth fission products form only trivalent chlorides under IFR process conditions. An example of equilibrium among elements that form trivalent chlorides is as follows:

$$
U \mathrm{Cl}_{3}+\mathrm{Pu}=U+\mathrm{PuCl}_{3}
$$

$$
U \mathrm{Cl}_{3}+\mathrm{C \theta}=\mathrm{U}+\mathrm{CeCl}_{3}
$$

Test results ${ }^{9.11}$ showed that the separation factors (SF) of trivalent actinides and rare earths are constant over wide ranges of phase compositions and redox conditions. The separation factor of a trivalent element with respect to uranium is given by:

$$
S F_{i}=\frac{M_{i} / N_{i}}{M_{u} / N_{u}}
$$


where $M_{i}=$ mole fraction of chloride element $i$ in salt

$N_{i}=$ atom fraction of element $\mathrm{i}$ in $\mathrm{Cd}$

$M_{u}=$ mole fraction of uranium chloride in salt

$N_{u}=$ atom fraction of uranium in $\mathrm{Cd}$

A separation factor equation for trivalent elements can be obtained using uranium as the reference element, as follows:

$$
D_{u}=\frac{D_{P u}}{S F_{P u}}=\frac{D_{N p}}{S F_{N p}}=\frac{D_{A m}}{S F_{A m}}=\frac{D_{C 0}}{S F_{C_{0}}}=\frac{D_{N d}}{S F_{N d}}=\ldots
$$

where $D_{i}=$ distribution coefficient of the $i^{\text {th }}$ element $=($ mole fraction in salt $) /$

(atom fraction in metal)

Process calculations are greatly simplified through the use of these separation factors because they have been found to be constant over wide ranges of redox conditions in the IFR salt/cadmium systems. Equation 4 indicates that the distribution coefficients of all elements can be calculated from the separation factors once the coefficient of one element is known. Separation factors were determined for the actinides and rare earths of interest to the IFR program. Distribution data for uranium, TRU elements, and some rare earths, which were obtained by several researchers during the development of the electrorefining and waste treatment processes, were analyzed by Koyama et al. ${ }^{9}$ Results for the LiCl-KCl eutectic at $500^{\circ} \mathrm{C}$ are shown in Fig. 3. The distribution coefficients in this figure are the ratios of weight fractions rather than mole fractions.

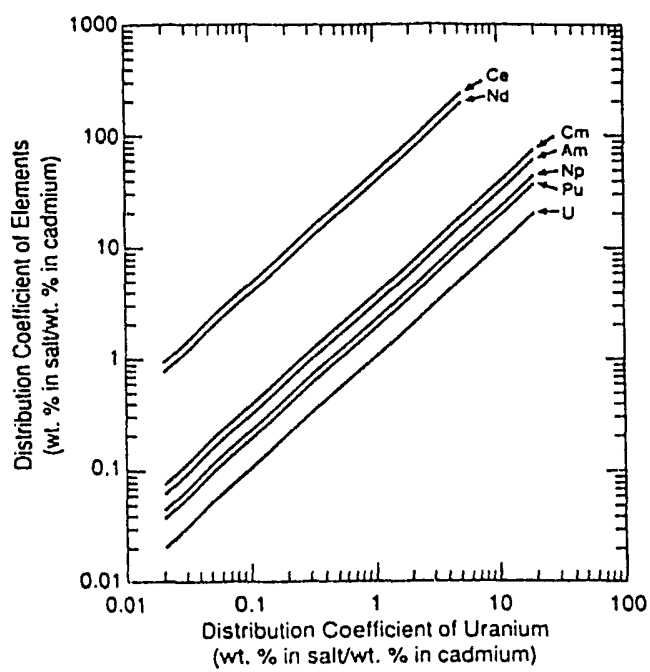

Fig. 3. Distribution Coefficients of Some Actinides and Rare Earths in $\mathrm{LiCl}-\mathrm{KCl} / \mathrm{Cd}$ Systems at $500^{\circ} \mathrm{C}$
Ackerman and Settle ${ }^{10,11}$ determined separation factors for several rare earths and related these data to the distribution coefficients for actinides. Table 2 gives the set of distribution coefficients derived from these data for conditions where the uranium distribution coefficient is 1.0. The values of the distribution coefficients for the trivalent elements are the same as the separation factors relative to uranium. Measurements by Ackerman and Settle ${ }^{11}$ of the distribution of several alkali metals and alkaline earths have confirmed that $\mathrm{Na}, \mathrm{K}, \mathrm{Cs}, \mathrm{Sr}, \mathrm{Sm}, \mathrm{Eu}, \mathrm{Y}$, and $\mathrm{Ba}$ will remain almost completely in the salt phase during the IFR fuel recovery process.

Table 2. Distribution Coefficients of Some Actinides and Rare Earths for $\mathrm{LiCl}-\mathrm{KCl}$ Eutectic/Cd at $500^{\circ} \mathrm{C}$. (Uranium Coefficient is 1.0 )

\begin{tabular}{|c|c|c|c|c|c|}
\hline Element & $\begin{array}{c}\text { Distribution } \\
\text { Coelficient }\end{array}$ & Ret. & Element & $\begin{array}{c}\text { Oistribution } \\
\text { Coelficient }\end{array}$ & Ret \\
\hline $\mathrm{Np}$ & 2.12 & 5 & $\mathrm{Ca}$ & 49 & 7 \\
\hline $\mathrm{Pu}$ & 1.88 & 5 & $\mathrm{La}$ & 130 & 7 \\
\hline $\mathrm{Am}$ & 3.08 & 5 & $\mathrm{Gd}$ & 150 & 7 \\
\hline $\mathrm{Cm}$ & 3.52 & 5 & $Y$ & 6000 & 7 \\
\hline $\mathrm{Pr}$ & 43.1 & 6 & $\mathrm{Sm}$ & $>1010$ & 7 \\
\hline $\mathrm{Nd}$ & 44.0 & 6 & $\mathrm{Eu}$ & $>1010$ & 7 \\
\hline
\end{tabular}

'mole fraction in salvatom fraction in cadmium.

The separation factors between rare earths and actinides show that these element groups can be effectively separated by liquid salt-metal extractions. The small separation factors among the actinides are a distinct advantage for the IFR concept, because it would be difficult to separate uranium and the minor actinides from plutonium to produce high purity plutonium in an IFR facility. The basis of the extraction process can be illustrated by considering the following: when a salt containing uranium, TRU elements, and rare earths is contacted with cadmium containing only uranium, the elements will redistribute themselves by means of exchange reactions to satisfy the equilibrium relationship of Eq. 4. The net result is that TRU elements and rare earths in the salt exchange with uranium in the metal, but larger fractions of the TRU elements transfer than rare earths. Uranium replaces TRU elements in the salt and eventually becomes part of the high-level metal waste. This uranium loss, which is less than $1 \%$ of the actinides fed to the electrorefiner. is not a serious penalty because it is depleted uranium.

Calculations ${ }^{10,12}$ using the measured separation factors have shown that adequate TRU recoveries and rare earth separations can be achieved by use of four to seven countercurrent, equilibrium stages with roughly equal volumes of metal and salt phases. Typical results are shown in Fig. 4, where the fractions of TRU elements and "extractable" rare earths remaining in the product salt are shown as functions of the metal/salt 


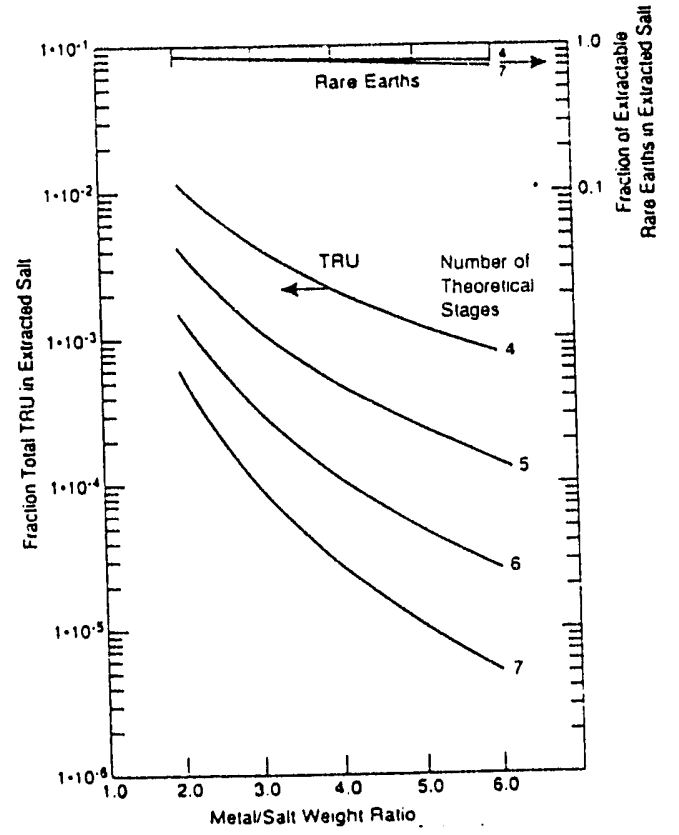

Fig. 4. Calculated Separations of TRU Elements from Rare Earths by Pyrochemical Extraction Processes

weight ratio and the number of equilibrium stages. The extractable rare earths do not include $\mathrm{Y}, \mathrm{Sm}$, and $\mathrm{Eu}$, which remain almost completely in the salt phase during extraction. With four theoretical stages and a metal/salt weight ratio of $4.0,99.8 \%$ of the plutonium and $99.0 \%$ of the minor actinides ( $\mathrm{Np}, \mathrm{Am}$, and $\mathrm{Cm}$ ) are recovered from the spent electrorefiner salt. About $80 \%$ of the extractable rare earths remains in the salt.

\section{TEST EQUIPMENT}

The equipment being developed for this pyrochemical extraction process is similar to the centrifugal contactor used for aqueous-organic solvent extractiun processes ${ }^{13}$ at room temperature. The densities of the light and dense phases of the aqueousorganic solvents are on the order of 0.9 to $1.2 \mathrm{~g} / \mathrm{mL}$. The coventional contactor (Fig. 5) includes a stationary housing and a central rotor. The dense and light phases enter the contactor through its inousing and flow downward through the annulus where mixing and equilibrating of the two phases take place. The mixture enters the centrifugal separating zone through the bottom of the rotor. The mixture flows upward and is separated into two phases by centrifugal force. The separated phases exit the contactor at the top of the rotor and flow countercurrently to the adjacent rotor and flow countercurrential design features ${ }^{14}$ of a conventional contactor include (a) stationary radial vanes under the rotor to break up the swirling of the dispersion. (b) enough power to pump liquids through

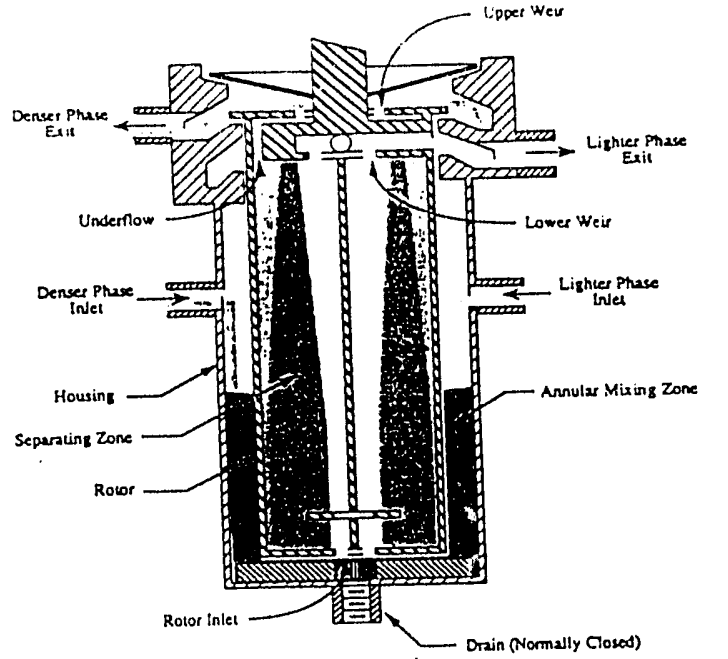

Fig. 5. Schematic of Conventional Contactor

the rotor, (c) axial vanes inside the rotor to provide uniform liquid spinning, and (d) appropriate dimensions for lower and upper weirs ${ }^{15}$ to enable the dispersion band to stay within the separating zone.

The high-temperature centrifugal. contactor $^{16}$ (called "pyrocontactor" here) operates at $500^{\circ} \mathrm{C}$ and handles molten salt with density of about $1.7 \mathrm{~g} / \mathrm{mL}$ and liquid metal with density of about $7.8 \mathrm{~g} / \mathrm{mL}$. Because of the high densities of the molten liquids, added energy is needed to provide good liquid mixing. A much longer drive shaft is needed to locate the motor bearing away from the high process temperature. To solve these problems, the pyrocontactor design incorporates (a) baffles in the housing and vanes on the rotor to enhance mixing and pumping of the salt and metal and (b) a spindle bearing at the housing bottom to reduce rotor vibration caused by the use of a much longer drive shaft. The inlets and outlets of the contactor are designed to allow the collection of liquid samples that provide information about the chemical compositions and concentrations of the feed materials and the effluents. This enables determination of the extraction efficiency of the contactor. Trains of these contactors can be used for multistage, continuous, countercurrent processing of metals and salts in other pyrochemical processes, as well as the one used for the IFR fuel cycle. This technology is attractive because a train of contactors provides a compact unit that can rapidly process a large quantity of material.

This pyrocontactor has a $4-\mathrm{cm}$-dia rotor and soon will be tested in the facility shown schematically in Fig. 6 . In addition to the contactor, the test facility has tanks for preparing feed materials, tanks for feeding the salt and metal solutions to the contactor at 


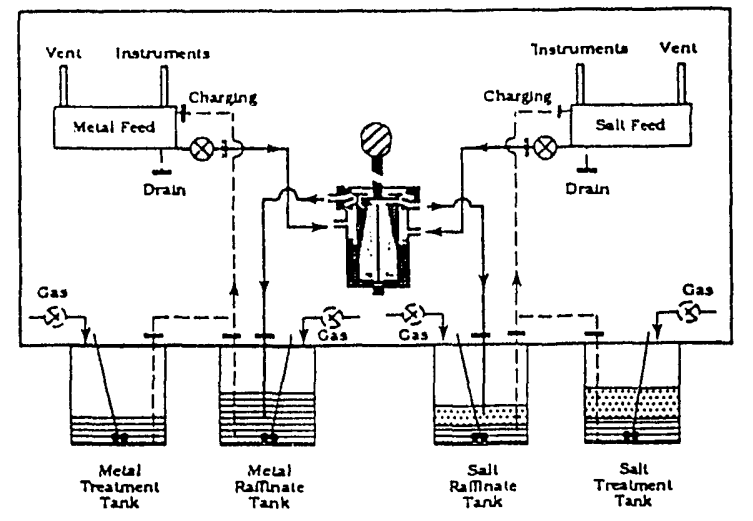

Fig. 6. Schematic of Pyrocontactor Test Facility

predetermined rates, and tanks for receiving the effluents. It was shown experimentally that the corrosion of Type 304 stainless steel by liquid cadmium and chloride salts at $500^{\circ} \mathrm{C}$ is low, and that the leach rate of Ni from 304 SS is small. Thus, Type 304 SS was chosen as the material of construction for these apparatuses. The pyrocontactor, tanks, and transfer lines are heated by resistance heating elements. The equipment is housed in a glovebox. The argon atmosphere of the box contains less than $15 \mathrm{ppm}$ moisture and less than $15 \mathrm{ppm}$ oxygen.

The fabrication and installation work for the test equipment and the glovebox is complete. The glovebox has been closed and leak checked, and the high-purity argon atmosphere is being established by a gas purification system. The test equipment and the heaters have been successfully tested (without any liquid) in both air and argon atmospheres at room and elevated temperatures. In the upcoming tests, the pyrocontactor will be tested at $500^{\circ} \mathrm{C}$ with molten $\mathrm{LiCl}$ $\mathrm{KCl}$ eutectic salt and liquid cadmium containing nonradioactive rare earths. The objective is to demonstrate that the pyrocontactor can operate satisfactorily without significant vibration or material corrosion at the high operating temperature, and that it will provide adequate mixing in the mixing zone and phase separation in the separation zone to obtain efficient extraction.

\section{TEST PLAN}

Five test series will be conducted.

(1) After the glovebox has been closed and filled with argon gas, tests will be conducted by feeding only one phase at a tims (first liquid cadmium and then molten $\mathrm{LiCl}-\mathrm{KCl}$ eutectic salt) to the contactor to demonstrate that a high temperature can be maintained throughout the system and that the contactor operates smoothly without significant vibration.
(2) Liquid metal and salt will be simultaneously fed to the contactor to demonstrate that adequate phase separation can be achieved.

(3) The first extraction test will use the reaction between cerium (dissolved in cadmium) and cadmium chloride (dissolved in the eutectic salt). Because this reaction is essentially quantitative and because the test involves only one extractable element, the determination of the contactor efficiency is relatively straightforward. During this and other extraction tests, samples will be collected from the feeds and the effluents; flow rates and temperatures of the feeds and effluents will be measured to determine the extraction efficiency of the contactor.

(4) The next extraction test will be conducted using lithium in the liquid cadmium to react with cerium chloride in the salt phase. This reaction is also quantitative and will provide additional data to determine the contactor efficiency.

(5) The initial demonstration of the TRU recovery process will be performed with rare earths as substitutes for the actinides (see below).

Using cerium as a stand-in for uranium, lanthanum for plutonium, and yttrium for rare earths, a similar set of separation factors is obtained (Table 3 ). The set of separation factors for $\mathrm{Ce}, \mathrm{L} a$, and $Y$ relative to cerium is very similar to the set of separation factors for $U, P u$, and rare earths relative to uranium. Calculations using the EXTRACT code ${ }^{11}$ were conducted to illustrate the compabability of extractions with only rare earths (REs). These calculations were made for one-stage extraction of a typical spent salt discharged from an electrorefiner using $1 \mathrm{at} \% \mathrm{U}$ in $\mathrm{Cd}$ and for a one-stage extraction of the pyrocontactor test salt (containing only $\mathrm{LaCl}_{3}$ and $\mathrm{YCl}_{3}$ ) using 1 at\% $\mathrm{Ce}$ in $\mathrm{Cd}$. Results are surrmarized in Table 4. About $82 \%$ of the TRUs and $11 \%$ of the REs are calculated to be extracted by 1 at\% $U$ in $C d$ from the electroretiner salt. The results are comparable to the calculated extraction of about $74 \%$ of the La and

Table 3. Comparison of Separation Factors

\begin{tabular}{|c|c|c|c|}
\hline \multicolumn{2}{|c|}{ IFA Process } & \multicolumn{2}{|c|}{ Pyrocontactor Tests } \\
\hline Elements & $\mathrm{SF}^{\mathrm{s}}$ & Elements & $\mathrm{SF}^{\circ}$ \\
\hline U (Bnsis) & 1 & Ce (Basis) & 1 \\
\hline $\mathrm{Pu}$ & 2 & La & 2 \\
\hline Nd & 44 & y & 88 \\
\hline$C_{A}$ & 60 & & \\
\hline L.. & 119 & & \\
\hline$y$ & 4040 & & \\
\hline
\end{tabular}

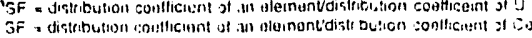


Table 4. Calculated Results Comparing One-Stage Extraction of Electrorefiner Spent Salts with Uranium to One-Stage Extraction of Pyrocontactor Test Salts with Cerium

\begin{tabular}{|c|c|c|c|c|}
\hline \multirow{2}{*}{ Concentration. } & \multicolumn{2}{|c|}{ Typical Electroreliner } & \multicolumn{3}{|c|}{} \\
\cline { 2 - 5 } & \multicolumn{2}{|c|}{ Salt Extraction } & \multicolumn{2}{|c|}{ Pyrocontactor Test } \\
\hline $\begin{array}{c}\text { mol\% in LiCl- } \\
\mathrm{KCl}\end{array}$ & Salts & $\begin{array}{c}\% \\
\text { Extracted }\end{array}$ & Salts & $\%$ Extracted \\
\hline 0.01 & $\mathrm{RE}(\mathrm{Cl})_{3}$ & 11 & $\mathrm{YCl}_{3}$ & 6 \\
\hline 0.001 & $\mathrm{TRU}(\mathrm{Cl})_{3}$ & 82 & $\mathrm{LaCl}_{3}$ & 74 \\
\hline
\end{tabular}

Extractant is $1 \mathrm{ar} U \mathrm{U}$ in $\mathrm{Cd}$.

Exuactant is $1 \mathrm{a} \% \mathrm{C \theta}$ in $\mathrm{Cd}$

$6 \%$ of the $Y$ by 1 at\% $\mathrm{Ce}$ in Cd for the contactor test salt. Thus, extraction of $\mathrm{La}$ and $Y$ chiorides from $\mathrm{LiCl}$ $\mathrm{KCl}$ using $\mathrm{Ce}$ in $\mathrm{Cd}$ closely resembles extraction of TRU and RE chlorides using $U$ in $C d$.

If these initial tests are successful, facilities will be built for process demonstrations with plutonium and irradiated fuel. Although several contactors in countercurrent flow may be used, the contactors will be abnit the same size as the present unit. No scale-up is required.

\section{REFERENCES}

1. C. E. TILL and Y. !. CHANG, "Evolution of the Liquid Metal Reactor: The Integral Fast Reactor (IFR) Concept," in Proceedings of the American Power Conference, Chicago, IL, April 1989, Vol. 51, pp. 688-691.

2. C. E. TILL, W. H. ARNOLD, and J. D. GRIFFITH, "The U.S. Liquid Metal Reactor Development Program," Presented at American Nuclear Society Topical Meeting .- Safety of Next Generation of Power Reactors, 1988.

3. L. BURRIS, R. STEUNENBERG, W. E. MILLER, "The Application of Electrorefining for Recovery and Purification of Fuel Discharged from the Integral Fast Reactor," AIChE Symp. Ser. 83 (254), 135-142 (1987).

4. T. R. JOHNSON, A. E. NEWMAN, M. A. LEWIS, and J. J. LAIDLER, "Treatment of High-Level Wastes from the IFR Fuel Cycle," American Chemical Society Meeting, Washington, DC, August 23-28, 1992.

5. T. R. JOHNSON and J. E. BATTLES, "Waste Management in IFR Fuel Cycle," Proceedings of Waste Management ' 91 , Vol. 1, 815, Arizona Board of Regents (1991).

6. J. P. ACKERMAN and T. R. JOHNSON, "New HighLevel Waste Management Technology for IFR Pyroprocessing Wastes," to be presented at the GLOBAL 93 International Conference and Technology Exhibition. Seattle, Washington, Sep. 12-17, 1993.
7. E. L. CARLS, R. J. BLASKOVITZ, and T. R. JOHNSON, "Test of Prototype Salt Stripper System for IFR Fuel Cycle," to be presented at GLOBAL '93, International Conference and Technology Exhibition, Seattle, Washington, Sept. 12-17, 1993.

8. J. P. ACKERMAN, "Chemical Basis for Pyrochemical Reprocessing of Nuclear Fuel," I\&EC Research 30(1), 141 (1991).

9. T. KOYAMA, T. R. JOHNSON, and D. F. FISCHER, "Distribution of Actinides in Molten Chloride Salt/Cadmium Metal Systems," J. of Alloys and Compounds, 189, 37.44 (1992).

10. J. P. ACKERMAN and J. L. SETTLE, "Partition of Lanthanum and Neodymium Metals and Chloride Salts between Molten Cadmium and Molten LiCl-KCl Eutectic," J. of Alloys and Compounds 177, 129-141 (1991).

11. J. P. ACKERMAN and J. L. SETTLE, Argonne National Laboratory, private communication, 1992.

12. J.P. ACKERMAN, "PYRO - A Sy'stem for Modeling Fuel Reprocessing," presented at American Nuclear Society Winter Meeting, San Francisco, CA, November 26-30, 1989.

13. Fi. A. LEONARD, "Recent Advances in Centrifugal Contactor Design," Sep. Sci. and Technol., 23 (12 \& 13), $1472-1487$ (1988).

14. R. A. LEONARD and M. J. STEINDLER, "Summary Report on the Development of Annular Centrifugal Contactors," Argonne National Laboratory Report ANL82-21, (June 1982).

15. R. A. LEONARD, "Prediction of Hydraulic Performance in Annular Centrifugal Contactors," Argonne National Laboratory Report ANL-80-57, (1980).

16. L. CHOW, R. A. LEONARD, T. R. JOHNSON, and G. F. VANDEGRIFT, "Development of a Centrifugal Contactor for Pyrochemical Processing," presented at $\mathrm{Pu} / \mathrm{U}$ Recovery Conference, Oak Ridge, TN, October 24-26, 1989. 

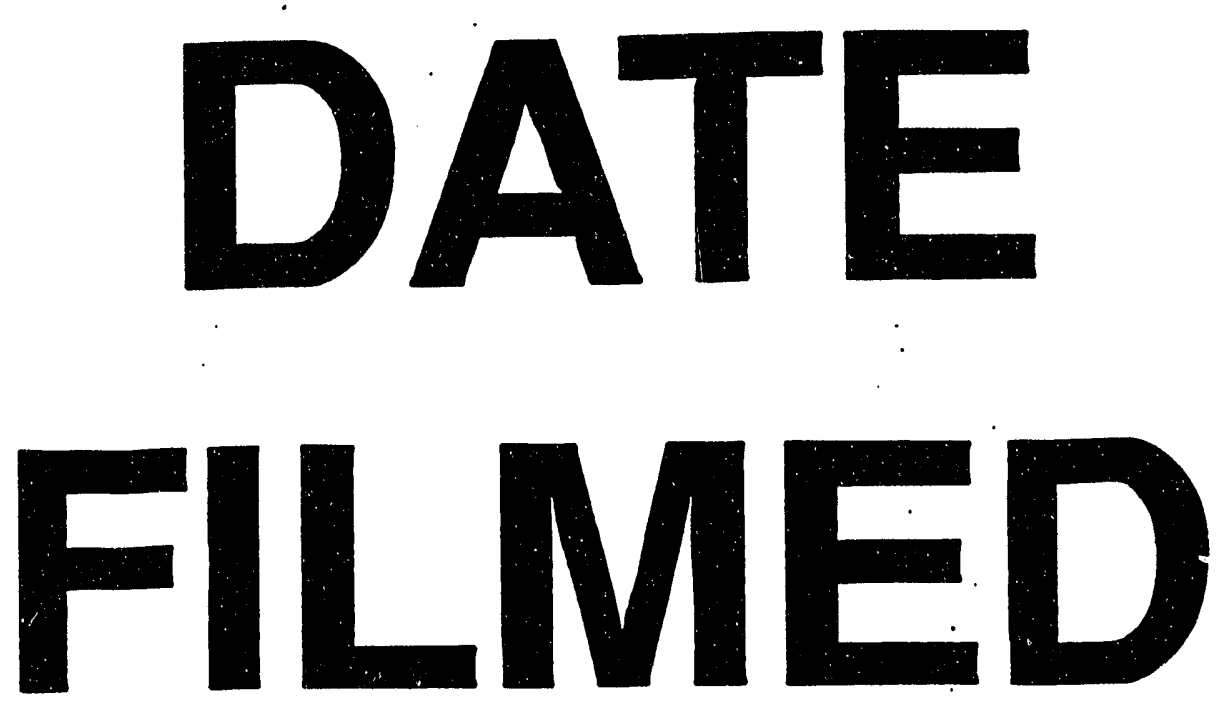

$11 / 4 / 93$
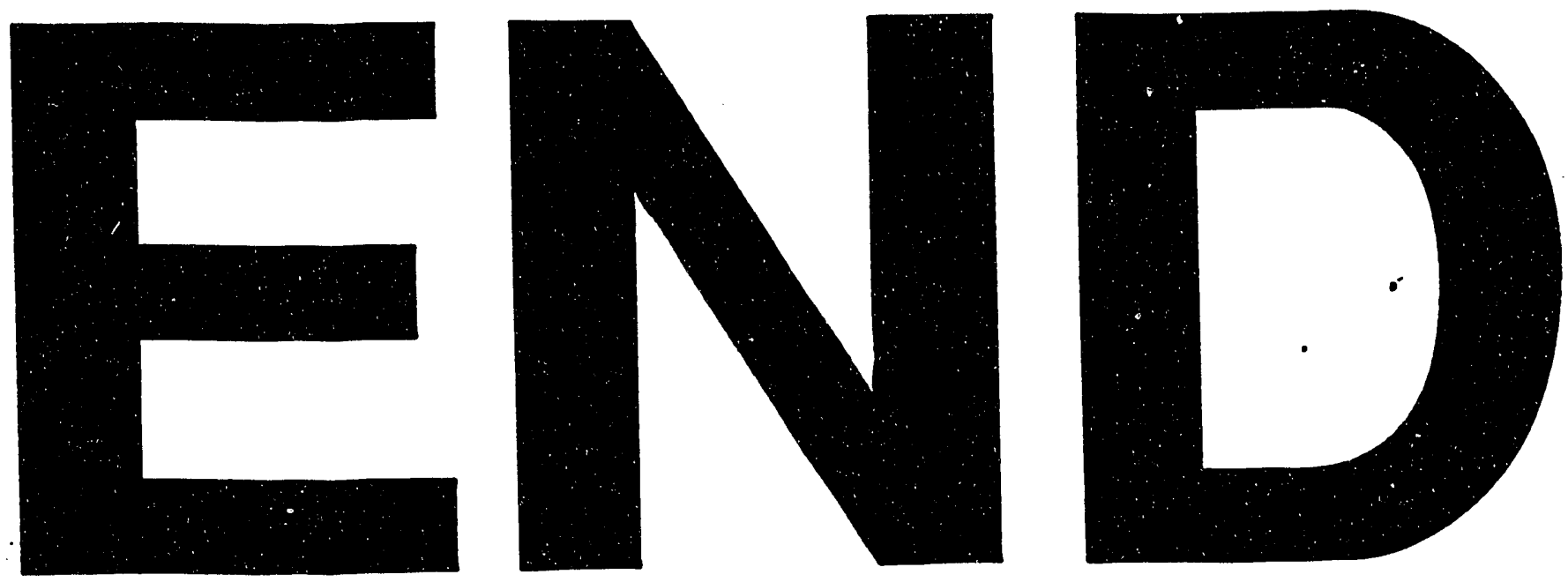
